\title{
The Application of Internet Financial Model in Targeted Poverty Alleviation
}

\author{
Jie Tian ${ }^{1}$, Kun Zhao, ${ }^{2, *}$ \\ ${ }^{1}$ School of Economy and Trade, Hebei GEO University. Shijiazhuang, Hebei, 050031, China. \\ ${ }^{2}$ Deloitte Touche Tohmatsu Limited, Beijing, 100738, China.
}

How to cite this paper: Jie Tian, Kun Zhao. (2020) The Application of Internet Financial Model in Targeted Poverty Alleviation. International Journal of Humanities, Arts and Social Science, 4(1), 35-39.

DOI: $10.26855 /$ jhass.2020.01.005

Received: March 22, 2020

Accepted: April 25, 2020

Published: May 12, 2020

*Corresponding author: Kun Zhao, Deloitte Touche Tohmatsu Limited, Beijing, 100738, China.

Email: zhaokun715@outlook.com

\begin{abstract}
Targeted poverty alleviation is a poverty control method as opposed to extensive poverty alleviation. With the Internet plus model of poverty alleviation, it plays an exemplary role in promoting poverty alleviation, carries out poverty alleviation publicity work, and delivers the arrival of the era of targeted financial services. Internet plus has become a national strategy, and the Internet finance model is also a positive energy for targeted poverty alleviation and poverty alleviation. We need to seize the characteristics of Internet finance and accelerate the connection and integration of poor area at the same time.
\end{abstract}

\section{Keywords}

Targeted Poverty Alleviation, Internet Plus, Internet Finance Model

\section{The Connotation of Targeted Poverty Alleviation Under the Internet Finance Model}

We are in the new era, facing new challenges. So we create the new economy for "Internet plus" to fully integrate function and optimize the distribution of elements of the Internet to play its role. The Internet innovation achievements with the combination of various fields has a significant boost innovation and productivity to the real economy. It is not hard to see that the internet is becoming a new and significant tool for the economic development in the new era. Its application is so common. The "Internet plus" combined with the targeted poverty alleviation which has provided poverty alleviation with more information and technical support in more areas. In other words, the original means of poverty alleviation are combined with Internet innovation technology to process the work of poverty alleviation. On the one hand, the Internet big data can help to analyze the information about the poverty alleviation work and improve the efficiency of the work. On the other hand, the big data can also make the work easier for the government to do. The government can always know the updates data well then they can carry out the proper policies.

In the era of "Internet plus", the application of modern science and technology are necessary for the targeted poverty alleviation work, so as to better achieve poverty alleviation and help the real poor. Through the Internet database, every facet can be involved so the targeted poverty alleviation work will be diversified and innovative. At the same time, it also adds new vitality to targeted poverty alleviation work, making it durable.

\section{Difficulties of Targeted Poverty Alleviation Under the Internet Finance Model}

With the rapid development of cities and towns, the backwardness and deficiencies of rural areas are gradually revealed, and the development has reached a level of no optimism. There are different types of difficulties we are facing: 
Backward rural market system.usually, the poor areas lack of infrastructure and public services, as well as poor transport conditions. However, the imperfect infrastructure and inconvenient transportation naturally affect the economic development of poor areas, and many poverty alleviation work projects need excellent infrastructure to support. Therefore, it is crucial for the government to boost infrastructure and traffic construction in poor areas. Embracing the "Internet plus", consumption gradually becomes decentralized and personalized, which brings a broad market for featured products in poor areas. We will encourage poor areas to develop "grassroots logistics", expand their markets, and spur entrepreneurship and innovation.

Rural market is characterized by small scale, poor circulation, and the traditional trades model still exists. The conventional thoughts of rural residents cannot produce enough economic benefits in such rural market system, which hinders the development of rural areas. The poor environment and the terrible transportation make the goods selling and buying much more difficult, which dampens the villagers living there to broaden their eyes and make money as well. Besides, the villagers are also troubled by the food safety that matters so much for the life of the villagers. It does delay the speed of the development of the countryside. Furthermore, it is reported that the current range of Internet popularization in China is not ideal and the overall penetration rate is relatively low, while the penetration rate of Internet technology in poor areas is slower. Therefore, in order to take "Internet plus" as a new idea of targeted poverty alleviation, firstly, we need to realize the full coverage of Internet technology in all poor areas of the country. In this stage, government departments should play a leading role in improving the popularization of Internet in poor areas. Second, we should carry out the Internet knowledge training in poor areas, so that people in the poor areas can understand and enjoy the significance of the Internet to life.

In the recent years, the work of the poverty alleviation has been getting better and better in China. But there are still some problems need to solve such as the main problems are what are the efficient and proper methods the government departments should carry out for the poverty alleviation work, how to rationally use poverty alleviation funds, how to properly plan the poor households, and how to make good use of poverty alleviation funds. In the new era of "Internet plus", the traditional poverty alleviation methods, the new "Internet plus finance" method will also bringing economic profit to the poverty alleviation work within a certain scope. And in this case, the supervision of social funds should be strengthen so that the use of social funds gets improved, putting an end to the phenomenon of idle social funds and unknown whereabouts.

Social participation is not high and the atmosphere is not strong. First, some collective private enterprises, individual business owners have a weak sense of social responsibility, and do not take the initiative to participate in social poverty alleviation, especially to support poor households to develop the economy, and have little interest in new industries. Slow and difficult to achieve results in a short time. The second is that the understanding of social poverty alleviation is vague, and that office benefits are the entire content of social poverty alleviation, ignoring the important content of supporting the development of farmers and increasing hematologist function. Supporting the development of public welfare undertakings is indeed an important part of poverty alleviation work, but public welfare undertakings can be resolved by applying for national infrastructure projects, and the shortage of funds to support poor households' industrial development is the biggest shortcoming of poverty alleviation work. This shortcoming did not attract the attention and support of the whole society.

Insufficient funds for rural construction. In the tide of vigorously developing social construction, compared with rural areas, the national government pays more attention to urban construction, which makes the rural construction funds are insufficient, resulting in its lagging behind cannot be improved. The shortage of funds for rural construction leads to the unsolved situation in poor rural areas, which makes the rural areas face the challenge. People tend to find a job at the more developing cities rather than their hometowns, which causes the loss of labor force, no one can use the rural construction, and the rural areas cannot continue to develop. The geographical location of rural areas is relatively remote, and the lack of rural development makes it hard for children living in rural areas to get advanced education. The backward traditional concept makes many parents do not support their children to study in school. This situation leads to the low level of rural education, which makes it difficult to understand and accept advanced ideas, technologies and strategies. The lack of talents makes it difficult for rural areas to develop in such an environment, which requires relevant departments to carry out targeted poverty alleviation.

\section{Strategies of Targeted Poverty Alleviation Under the Internet Financial Model}


In order to make the internet play its role into the work of the targeted poverty alleviation work, we should figure out more strategies. Following is some strategies can be carried out. Targeted poverty alleviation in rural areas can play a variety of roles to achieve targeted poverty alleviation in rural areas under the background of big data. Internet financial can make precision rural poverty alleviation logical and normative, build rural poverty alleviation work fine for long-term mechanism to provide technical safeguard, make use of the data collection, induction, sorting and analyzing precision formulate scientific and effective rural poverty relief system, precision makes the rural poverty reduction policy can implement to local, truly benefit the people. The advantage of the Internet has the characteristics of convenient, accurate, comprehensive analysis of its data and the use of more representative villages resulted in poverty alleviation. They are in need of help with the Internet to poverty alleviation work in a transparent, attract social people from all walks of life to reduce the pressure on the national government, promote the development of many facets of the country. The introduction of Internet finance can also help rural targeted poverty alleviation achieve scientific management, and then complete the "six precise" work, making the work goal-oriented. And it can also make the work process more accurate. The application of the internet can make the work and data of the work of the poverty alleviation more efficient. So as to build a well-run work processing in a regular and orderly environment.

\subsection{Targeted Poverty Alleviation Based on the Construction}

The first network of party construction service platform has been started, whose functions include: the administrative examination and approval and public service, and providing free and effective information on getting rich and agriculture to poor households. With the use of information platform construction and timely updated information, poverty alleviation work can be truly accurate. However, both targeted poverty alleviation and targeted poverty alleviation rely on the efforts of primary-level party organizations to carry out the poverty alleviation work. We should intensify publicity on measures and policies for the processing of the poverty alleviation and development.

\subsection{Targeted Poverty Alleviation of the Education}

Education is always the crucial thing for a country. It can cultivate so many talents of various areas, which are significant and makes great contribution to the development of the country. Especially in the new Internet era, education will be promoted to enable people in poor areas to acquire relevant knowledge and skills more effectively and quickly. The shortage of talents has always been a problem that troubles rural construction. The lack of education resources in rural areas and the influence of the conventional teaching ideas make students here not available for rural construction, which requires the use of Internet finance to supply educational resources in poor rural areas. Internet provides a cloud teaching mode, which makes the students of remote areas be able to get high quality education resources and take the network as the medium of learning knowledge. Rural villagers can also develop their professional skills through the network education resources to do the village mutual learning and improve their ideological level, raise the employment of the impoverished rural population and construction ability, to carry out the rural precision for poverty alleviation. This system of obtaining other educational and teaching resources in colleges and universities through the network and teaching students through multimedia equipment complete the education and training of talents in the countryside. Teenagers are the hope of rural construction so we need to give them corresponding education resources, cultivate their learning ability and comprehensive quality. The qualified education can help them to expand their eyesight and make the way for them to be exposed to the modernization, then to help making the continuous development of the rural construction. In addition, not just school-age students need education resources for learning, even adult adults also needs education to improve their skills and enrich their knowledge, so the vocational skills training is one of the network for poor rural villagers to transfer principle of advanced production and management ideas, drive them actively exploring the road of rural poverty. We will train new types of rural villagers, improve their ability to start businesses and find jobs, promote the development and progress of poor villages, and help all of them realize their worth.

\subsection{Green Support and Greater Financial Support}

In November 2013, the government proposed the targeted poverty alleviation. In 2014, the central government completed the design of the targeted poverty alleviation work mode, then the targeted poverty alleviation work officially started. Focusing on targeted poverty alleviation needs to seize the opportunity of the development of 
Internet finance, a series of poverty alleviation practices have been carried out in various regions, and seven financial targeted poverty alleviation modes have finally been formed. The poverty alleviation mode of Internet finance is one of them. The Internet has brought significant advantages to information dissemination and resource conversion. While building a community of shared destiny in cyberspace, we should broaden the implementation path of "Internet plus financial poverty alleviation" and rebuild the relationship between people and the Internet and between people and society. Such as the government to the electronic commerce as a key work of poverty alleviation and development, encouraging measures aimed at bolstering area, integrating the advantage products, guiding the electric business enterprise to help local agricultural products online sales platform, the construction of electricity precise experimental base for poverty alleviation, connecting rural agricultural production and city big market, with the help of the Internet to build a new environment for poverty alleviation. We also need to speed up the rural electronic commerce development. In the process of rural e-commerce development, large commercial financial institutions play an important role, but we also want to give full play to the role of the small and medium-sized commercial financial institutions, increase financial support for accurate poverty alleviation, at the same time increase the size of the different financial institutions financing, credit of technology and information cooperation, jointly provide efficient financial services to precise poverty alleviation and development.

\subsection{Broadening the Paths of Poverty Alleviation}

Targeted poverty alleviation is different from traditional poverty alleviation, but it still follows the traditional poverty alleviation system and path, and it is also guided by the government to a large extent. It is the market mechanism that helps to form the mode of the. However, the targeted poverty alleviation work of Internet finance model must coordinate and handle the relationship between the government and the market to achieve sustainable development. In order not to affect the enthusiasm of financial institutions in poverty alleviation, the government cannot force financial institutions to develop and alleviate poverty, but should urge financial institutions to alleviate poverty under the guidance and incentives of policies. This requires the government and the market to make concerted efforts to give full play to the comparative advantages of micro finance, cooperative finance and other financial poverty alleviation models, and to promote the cooperation of financial institutions based on comparative advantages. In the cooperation of financial institutions, play a leading role, strengthen the service function, link the cooperation between poor areas and developed areas, and different financial institutions, realize the complementary advantages of poverty alleviation, and make full use of resources. On this basis, we should build a good social environment, improve the rural credit system, create a model of poverty alleviation through Internet finance, give play to the role of demonstration and promotion, do a good job in poverty alleviation publicity, and deliver the positive energy of targeted poverty alleviation through financial services. At the same time, we should grasp the characteristics of network finance, accelerate the construction of transportation and logistics systems in poor areas, strengthen the cultivation of talents in the Internet + poverty alleviation system, and train a group of rural youth to start businesses, and promote economic development in poor areas.

\subsection{Making Accurate Positioning and Enhancing the Effect of Poverty Alleviation}

Targeted poverty alleviation must not only target the poor, but also solve the problems of "who supports" and "how to support". The poverty alleviation model of Internet finance has a strong influence on poverty alleviation target education, poverty alleviation associations, and poverty alleviation space expansion. The Internet-based financial poverty alleviation model should play an active role in targeted poverty alleviation, aiming at targeted rural poverty alleviation via the Internet, and making positive contributions to the scale and industrialization of targeted poverty alleviation. Internet finance micro-poverty alleviation is to provide the poor people with various financial services, provide them with opportunities to borrow, invest, produce and generate income, improve the precision of financial poverty alleviation funds and technologies, and avoid rent-seeking phenomenon in the use of poverty alleviation funds. At the macro level, Internet finance poverty alleviation mainly focuses on the financial poverty alleviation of industrial projects. In other words, the development of poverty alleviation projects has helped poor people find an export for poverty alleviation. In this process, financial enterprises should not only pay attention to the capital and technology investment for targeted poverty alleviation, but also pay attention to risk prevention and control, and the process and effects of poverty alleviation. For example, in the development of poverty alleviation projects, the poor households should be registered, and the performance evaluation should be emphasized. It also requires the financial enterprises to strengthen cooperation with government, to incorporate 
Internet thinking into rural comprehensive management in the poor area of the data such as population, land, weather, address information input system, comprehensive management of agricultural big data, using the digital management reversed transmission precision of rural poverty alleviation, to expand the space of precision for poverty alleviation. At the same time, the advantages of the Internet should be brought to everyday life. It is necessary to publicize the correct value orientation, strengthen the spiritual care and guidance education for the poor, cultivate the people's awareness of poverty alleviation in the poverty-stricken areas, and win the battle of poverty alleviation.

In summary, with the accelerating trend of integration of China's financial poverty alleviation model, Internet financial institutions will play an increasingly prominent role in targeted poverty alleviation. Therefore, the government should further promote and support the development of the poverty alleviation model of online finance by financial institutions, effectively combining the government's fiscal poverty alleviation model with Internet finance and other poverty alleviation models to promote the sustainable and coordinated development of poverty alleviation.

\section{Funding}

The study is funded by The project of Hebei Province Federation of social science circles [Z020220190115] Research on the construction of horizontal inter-governmental cooperation mechanism in the governance of poverty zero in Hebei province.

\section{References}

GAO, Jie, Wang-ke LIAO, and Yu-tong FENG. (2017). “The Research Status of 'Internet Plus' Characteristic Agricultural Industrial Targeted Poverty Alleviation in Dali Prefecture.” Management \& Technology of SME 6 (2017): 20.

JIN Yuqing, DI Guangcai, MA Xiaoxia ,et al. (2018). Targeted Poverty Alleviation Strategy in Wuwei Based on "Internet + Agriculture”. [J]. Business \& Economy, 2018.

Qian, Anni, and Chien-Yin Chen. (2020). “Accurate Model of the Internet Financial Poverty Alleviation Based on the Multi-agent and the Data Mining.” Data Processing Techniques and Applications for Cyber-Physical Systems (DPTA 2019). Springer, Singapore, 2020. 1377-1383.

Shuxing, Xiao, and Bai Fuchen. (2018). Linkage Mechanism of “Internet Plus Targeted Poverty Alleviation” Theoretical Logic and Case Evidence. 2018 International Conference on Economy, Management and Entrepreneurship (ICOEME 2018). Atlantis Press.

Wang Hao. (2016). Financially targeted poverty alleviation model. [J] China Finance, 2016 (22): 25-26.

Yang Yunlong, Wang Hao, He Wenhu. (2016). Research on China's financial precision poverty alleviation model under the “quaternary structure”. [J] Western Finance, 2016 (09):47-53.

Zhang Qiangding. (2016). “Internet + Targeted Poverty Alleviation” Study 1-Take Henan Province as an example. [J] Economic Research Guide, 2016 (27): 23-25.

Zhang Zhixin, Yang Yuyu. (2018). Department of Logistics. The Exploration and Proposal of Aggie Butt Targeted Poverty Alleviation [J]. Journal of Jiangsu University. 